\title{
Notícia: Centenário de B. F. Skinner (1904-1990): Uma Ciência do Comportamento Humano para o Futuro do Mundo e da Humanidade
}

\author{
Rachel Nunes da Cunha ${ }^{2}$ e Luciana Patrícia Silva Verneque ${ }^{3}$ \\ Universidade de Brasília
}

\section{News: Centennial for B. F. Skinner (1904-1990): A Science of Human Behavior Toward a World and Humanity's Future}

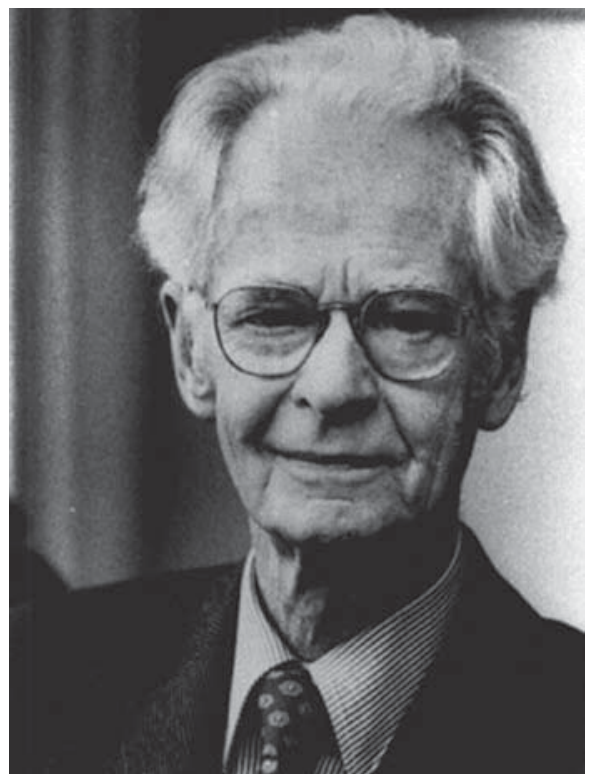

Figura. B.F. Skinner, fotografia disponível no portal da B. F. Skinner Foundation.

O primeiro número do volume 20, referente ao ano de 2004, da revista Psicologia: Teoria e Pesquisa, registra o centenário de B. F. Skinner, o fundador da Análise Experimental do Comportamento e do Behaviorismo Radical. Esse registro é uma homenagem ao eminente psicólogo, considerado um dos mais importantes pensadores e cientistas do século XX.

Skinner, nasceu Burrhus Frederic Skinner, aos vinte dias de março de 1904, na pequena cidade rural, Susquehanna, no Estado da Pennsylvania. Concluiu o segundo grau em 1922, no colégio Susquehanna High School e, no mesmo ano iniciou os estudos universitários, no Hamilton College, em Clinton, New York. Graduou-se em literatura inglesa e línguas românicas, em 1926. Depois de formado, Skinner pensou em seguir a carreira de escritor, idéia que foi abandonada e, em 1928, decidiu-se pelo curso de pós-graduação em psicologia, para o qual se inscreveu no programa de Psicologia Experimental, em Harvard University. Obteve os títulos de Master e PhD, em 1930 e 1931, respectivamente. Após

1 As autoras agradecem à B. F. Skinner Foundation (Fundação B. F. Skinner) pela permissão de publicar esta fotografia de B. F. Skinner. Site: http://www.bfskinner.org

2 Endereço: Universidade de Brasília, Instituto de Psicologia, Brasília, DF, Brasil 70910-900. E-mail:rdacunha@unb.br

3 Aluna do programa de Pós-graduação em Psicologia, do Instituto de Psicologia. Mestrado em Psicologia, da Área de Concentração em Processos Comportamentais. o doutoramento, permaneceu em Harvard, até 1936, com um apoio financeiro para fazer pesquisas. Ainda em 1936, ele se mudou para Minneapolis, para assumir as atividades de professor e de pesquisador na University of Minnesota, iniciadas no ano letivo de 1937. Na University of Minnesota, Skinner encontrou espaço livre para ensinar e pesquisar o behaviorismo que ele vinha desenvolvendo desde os tempos de Harvard. Em Minneapolis, ele conheceu Yvonne Blue, com quem se casou e teve duas filhas, Julie e Deborah.

Em 1945, tornou-se chefe do Departamento de Psicologia da Indiana University; onde Skinner começou a trabalhar nos manuscritos do Verbal Behavior e do Walden II, publicados em 1957 e 1948, respectivamente. Em 1948, ele retornou a Harvard, como convidado para pesquisar e ensinar naquela Universidade, onde permaneceu até a sua aposentadoria, em 1974, aposentou-se como Harvard's Edgar Pierce Professor of Psychology.

Sem nenhuma dúvida, Skinner foi um dos mais influentes psicólogos do século XX, ou seja, da psicologia científica moderna. Estabeleceu as bases metodológicas para o estudo científico do comportamento de organismos não humanos, em laboratório, sem perder de vista o comportamento humano, seja ele simples ou complexo, do indivíduo só ou em grupo, enfim, de todas as possibilidades da ação humana. Skinner desenvolveu também instrumentos básicos para o estudo sistemático das relações comportamentais do organismo com o seu meio ambiente. Nesse sentido, uma metodologia foi desenvolvida e denominada de Análise Experimental do Comportamento. $\mathrm{O}$ ambiente experimental para as pesquisas de laboratório foi por ele, habilidosamente, construído e denominado de câmara de condicionamento operante (também conhecida por caixa de Skinner). Do instrumental criado e construído por Skinner, o mais genial, além da câmara operante, foi o registro cumulativo (cumulative recorder), que permite um registro minucioso do comportamento em tempo real, que pode ser mensurado pela taxa de respostas. O modelo experimental de Skinner foi inovador em vários aspectos aos até então utilizados pela psicologia experimental. Skinner introduziu a análise do sujeito como seu próprio controle; as contingências de reforço, como instrumentos de análise funcional das relações comportamentais com o meio ambiente e a taxa de respostas como uma medida comportamental importante. Tratou o comportamento como um evento natural, com regularidade e passível de ser estudado cientificamente e, com seu modelo de ciência, estudou o comportamento dos organismos, preocupado principalmente com o comportamento humano, interessado em identificar as variáveis das quais o comportamento é função. 
A ciência do comportamento que Skinner propôs não estaria completa se não tivesse uma base filosófica. Para tanto, ele sistematizou as bases epistemológicas e filosóficas dessa ciência sob a denominação de Behaviorismo Radical, que está, principalmente, apresentada no livro About Behaviorism, publicado em 1974.

Em seu primeiro livro, The Behavior of Organisms - An Experimental Analysis, Skinner claramente distingue o comportamento operante do comportamento respondente, a partir das variáveis controladoras envolvidas nessas duas relações comportamentais e, a partir de então, ele enfatiza as relações funcionais operantes, as quais estão sob o controle das contingências de reforçamento, enquanto as relações funcionais respondentes estão sob o controle de estímulos eliciadores. The Behavior of Organisms foi o primeiro livro utilizado para ensinar os princípios da ciência do comportamento tanto em Minnesota, por Skinner como em Columbia (Columbia University) por Fred Keller e William Schoenfeld. Um livro texto mais didático tornou-se necessário para o ensino da análise do comportamento, e assim nasceu o Principles of Psychology - A Systematic Text in the Science of Behavior, publicado em 1950, por Keller e Schoenfeld, hoje um clássico da Análise do Comportamento. Em 1953, Skinner também publica um livro texto para ser utilizado em disciplina que deveria atender a estudantes de vários cursos na universidade em Harvard, trata-se de Science and Human Behavior, que em 2003 mereceu uma seção comemorativa do cinqüentenário de publicação, no Journal of the Experimental Analysis of Behavior. O livro Science and Human Behavior tem duas partes, uma dedicada à ciência do comportamento humano, com questões filosóficas, metodológicas e conceituais e outra parte dedicada às questões sociais, as agências controladoras de comportamento, como por exemplo, o estado, a igreja, a psicoterapia. Neste livro, Skinner nos mostra a extensão da análise do comportamento às questões complexas do comportamento humano. O conhecimento das variáveis controladoras do comportamento, ou seja, das contingências de reforçamento, nos permite controlar e predizer o comportamento, possibilitando o desenvolvimento de tecnologias comportamentais para estabelecer novas contingências comportamentais em diversos contextos da vida cotidiana.

Publicado em colaboração com C. B. Ferster, em 1957, Schedules of Reinforcement, produto de mais de cinco anos de pesquisa. É um relato sistemático de técnicas experimentais de estudo em laboratório, onde vários esquemas de reforçamento foram investigados, tais como, razão fixa, intervalo fixo, intervalo variável, razão variável e alguns dos vários esquemas complexos. O livro inclui um glossário de mais de cem termos.

Skinner foi um cientista que se ocupou de fazer análise funcional do seu comportamento de pesquisar, tornando-se ele próprio sujeito de suas análises, como também, demonstrou que a análise experimental do comportamento versa sobre o comportamento humano. Um exemplo sistemático dessa análise encontra-se no Verbal Behavior. E como cientista, Skinner se preocupou com todos os aspectos que um bom cientista deve se concentrar: produção e divulgação de conhecimento e formação de pesquisadores; empreendimentos científicos, como organização de periódicos, sociedades e entidades científicas; e foi parcimonioso e rigoroso com o método, com os princípios básicos e com a filosofia da ciência que propôs para estudar e compreender o comportamento humano. Foi inovador e muito contribuiu para a Ciência, defendendo a extensão dos métodos científicos ao campo do comportamento humano, que muitas vezes lhe fora negado, devido às práticas seculares de explicação explanatórias e fictícias, desprovidas de características científicas e lógicas. Skinner foi contundente em se opor ao emprego de entidades mentais como variáveis explicativas do comportamento; ao contrário, defendeu que os comportamentos privados, como por exemplo, pensamento, conhecimento, emoções, devessem ser estudados à luz da ciência do comportamento, a partir de uma análise funcional, a qual permite identificar as variáveis das quais esses tipos de comportamento são função e, este procedimento não é diferente do procedimento utilizado para investigar qualquer tipo de relação comportamental que envolva um tipo de comportamento público.

A imensa contribuição de B. F. Skinner à Ciência em Geral, à Psicologia, aos Educadores, à Sociedade e à Cultura é notória e inquestionável. O legado que Skinner nos deixou é notável. A sua profícua obra, de 1930 até 1990 (ano de sua morte), ou seja, 60 anos de produção científica contínua, engloba centenas de de artigos e vários livros publicados e ainda, palestras, conferências, aulas, seminários, formação de pesquisadores, entrevistas, anos de pesquisas em laboratórios, durante os sete dias da semana. Esse legado que herdamos muito tem a contribuir para o desenvolvimento da ciência do comportamento, que tem demonstrado ser um caminho para permitir um futuro melhor do mundo e da humanidade. A ciência do comportamento humano, no modelo de Skinner não é uma ficção aos moldes de Walden II e sim um conjunto de regras e de instrumentos conceituais que permitem mudanças no ambiente e conseqüentemente mudanças no comportamento, a partir de descrições cada vez mais precisas do complexo comportamento humano. Após Skinner, os objetivos da ciência - previsão e controle -, tornaram-se possíveis e realidade aos diversos campos da ação humana.

Em memória de B. F. Skinner e em celebração do centenário do seu nascimento, agradecemos pela sua dedicação à Ciência e pelo conhecimento acerca do comportamento humano que ele nos legou.

A principal contribuição de Skinner para a psicologia foi ter estabelecido as bases da ciência do comportamento, aprimorando a sua metodologia e filosofia, o que possibilitou analisar diversos problemas que o homem tem enfrentado, com perspectivas de desenhar uma cultura de paz e harmonia para a humanidade. Mas muito se há de fazer para se alcançar esse estágio de desenvolvimento cultural.

B. F. Skinner morreu dia 18 de agosto de 1990, aos 86 anos, um dia depois de terminar a revisão do seu último artigo, Can psychology be a science of mind? publicado no periódico American Psychologist.

O centenário de B. F. Skinner tem merecido registro e celebrações de várias entidades científicas que representam os diversos campos da psicologia.

\author{
Recebido em 20.04.2004
}

Aceito em 20.04.2004 